\title{
Evidence for Enhanced Land-Atmosphere Feedback in a Warming Climate
}

\author{
Paul A. Dirmeyer, ${ }^{*}$ Benjamin A. Cash, ${ }^{*}$ James L. Kinter III, ${ }^{*}{ }^{+}$Cristiana Stan, ${ }^{*}$ Thomas Jung, ${ }^{*}$ \\ Lawrence MarX,* Peter Towers, ${ }^{*}$ Nils Wedi, Jennifer M. AdAms,* Eric L. Altshuler,* \\ BoHuA HuAnG, ${ }^{+}, *$ EMILIA K. Jin,${ }^{@,+}$ AND Julia MANGANELlO* \\ * Center for Ocean-Land-Atmosphere Studies, Calverton, Maryland \\ ${ }^{+}$George Mason University, Fairfax, Virginia \\ \# European Centre for Medium-Range Weather Forecasts, Reading, United Kingdom \\ ${ }^{@}$ Korea Institute of Atmospheric Prediction Systems, Seoul, South Korea
}

(Manuscript received 10 August 2011, in final form 23 January 2012)

\begin{abstract}
Global simulations have been conducted with the European Centre for Medium-Range Weather Forecasts operational model run at T1279 resolution for multiple decades representing climate from the late twentieth and late twenty-first centuries. Changes in key components of the water cycle are examined, focusing on variations at short time scales. Metrics of coupling and feedbacks between soil moisture and surface fluxes and between surface fluxes and properties of the planetary boundary layer (PBL) are inspected. Features of precipitation and other water cycle trends from coupled climate model consensus projections are well simulated. Extreme 6-hourly rainfall totals become more intense over much of the globe, suggesting an increased risk for flash floods. Seasonal-scale droughts are projected to escalate over much of the subtropics and midlatitudes during summer, while tropical and winter droughts become less likely. These changes are accompanied by an increase in the responsiveness of surface evapotranspiration to soil moisture variations. Even though daytime PBL depths increase over most locations in the next century, greater latent heat fluxes also occur over most land areas, contributing a larger energy effect per unit mass of air, except over some semiarid regions. This general increase in land-atmosphere coupling is represented in a combined metric as a "land coupling index" that incorporates the terrestrial and atmospheric effects together. The enhanced feedbacks are consistent with the precipitation changes, but a causal connection cannot be made without further sensitivity studies. Nevertheless, this approach could be applied to the output of traditional climate change simulations to assess changes in land-atmosphere feedbacks.
\end{abstract}

\section{Introduction}

The Fourth Assessment Report (AR4) of the Intergovernmental Panel on Climate Change projects an increase in global mean precipitation over the next 100 years but substantial decreases across much of the subtropics and in midlatitudes during summer (Meehl et al. 2007). The AR4 also projects large areas with significant decreases in soil moisture and increasing surface evapotranspiration. The role of feedbacks between soil moisture and climate is mentioned (Randall et al. 2007), but the processes and impacts of land-climate interactions through the global water cycle were only beginning to be understood in simulations of current climate.

Corresponding author address: Center for Ocean-LandAtmosphere Studies, 4041 Powder Mill Rd., Suite 302, Calverton, MD 20705.

E-mail: dirmeyer@cola.iges.org
Dirmeyer (1999) showed that seasonal hindcasts in a global climate model were sensitive to realistic soil wetness boundary conditions. A number of modeling studies since then investigated this sensitivity on subseasonal to seasonal time scales (e.g., Schär et al. 1999; Dirmeyer 2000; Douville 2002, 2003; Koster and Suarez 2003). Climate models allowed for the assessment of soil moisture memory and its role in climate variations (e.g., Koster and Suarez 2001; Schlosser and Milly 2002; Seneviratne et al. 2006a) and feedbacks through the water cycle (e.g., Dirmeyer 2001, 2005, 2006; Koster et al. 2002). These studies eventually led to large multimodel experiments to describe the role of soil moisture in subseasonal to seasonal climate variability (Koster et al. 2006; Guo et al. 2006) and to predictability (Koster et al. 2010, 2011). From this work arose the notion of an inherent degree of coupling between soil moisture and climate that varies in space and time. 
Much less has been done to examine the connection between the terrestrial water cycle and the atmosphere in the context of climate change. AR4 considered only seasonal mean statistics of the hydrologic cycle (Meehl et al. 2007; Randall et al. 2007). Seneviratne et al. (2006b) appraised how regions of land-atmosphere coupling may shift over Europe during the next century in regional model simulations and inferred global changes from seasonal mean data from AR4 simulations. Seneviratne et al. (2010) presented a conceptual model of how climate change may push certain locations from radiationlimited to moisture-limited evaporation regimes, where the feedback loop from land to atmosphere via the water cycle is in effect (Dirmeyer et al. 2009). However, there have not been, to our knowledge, climate change simulations performed with global models expressly to examine trends in land-climate interactions or to examine the water cycle changes expressed at very short time scales.

The classic metrics of land-atmosphere coupling applied to weather and climate models (e.g., Koster et al. 2006; Wang et al. 2007) rely on statistics from ensemble simulations and specially designed sets of sensitivity experiments that are not part of typical climate change simulations, although proxies for coupling strength have been deduced from more readily available data and variables (e.g., Koster and Suarez 2004; Betts 2004; Seneviratne et al. 2006b; Dirmeyer et al. 2009). It has been difficult to quantify the connection between soil moisture variations and atmospheric response in variables like temperature or precipitation because several steps are involved. In the water cycle, soil moisture may have a controlling effect on evapotranspiration. Any signal in this surface moisture flux must then find its way through the near-surface atmosphere, competing with other sources of variability and the receptiveness of the mean atmospheric state, to be detected as an attributable anomaly. The same is true in the energy cycle, where both latent and sensible heat fluxes at the surface may be gateways between soil moisture forcing and atmospheric response. Highly nonlinear processes such as convective triggering complicate this connection (Findell and Eltahir 2003; Findell et al. 2011; Ferguson and Wood 2011).

Recently, Santanello et al. $(2009,2011)$ deduced a method to quantify the relative magnitudes of surface fluxes, lateral advection, and entrainment at the top of the daytime planetary boundary layer (PBL) in affecting the heat and moisture content of the PBL. The effect of these contributions can then be evaluated in terms of their effect on the vertical profile of the atmosphere, and their effect on the formation of clouds or convective precipitation. Knowledge of near-surface temperature and humidity at the start of daytime boundary layer growth (just after sunrise) and before collapse (around sunset), mean daytime surface fluxes, and estimates of lateral heat and moisture advection from the largescale circulation are combined with an assumption of a well-mixed PBL to deduce entrainment rates as a residual. From these quantities, expressed in units of energy per unit mass of air within the PBL, the relative impact of surface fluxes can be estimated. Combined with existing metrics of soil moisture-surface flux coupling, which can now be expressed in units of energy flux (Guo et al. 2006; Dirmeyer 2011), a means exists to quantify the feedback circuit of soil moisture to important PBL states and to quantify their sensitivities in changing conditions.

In this paper, we examine recent high-resolution (in space and time) global time-slice simulations of climate from the late twentieth and late twenty-first centuries. These simulations provide data resolving the diurnal cycle, which not only makes possible the estimation of the coupling metrics mentioned above, but also the effects of climate change on short time-scale hydrologic phenomena such as episodes of flash flooding. The global model and two multidecadal simulations are described in the next section. Section 3 describes aspects of the global water cycle in the model. Coupling between soil moisture and the atmosphere is diagnosed in section 4 in two steps-from soil moisture to surface fluxes, and from surface fluxes to the PBL-and then the two segments are combined in a single metric. Discussion and conclusions are presented in section 5 .

\section{Description of model and simulations}

The simulations examined here are from 47-yr integrations of the Integrated Forecast System (IFS; Molteni et al. 1996; ECMWF 2009) general circulation model (GCM). These simulations were conducted as part of Project Athena (Kinter et al. 2012, manuscript submitted to Bull. Amer. Meteor. Soc.), which addresses the hypothesis that increasing climate model resolution to accurately resolve mesoscale phenomena can dramatically improve the fidelity of the models in simulating climate.

We have performed long simulations representing the late twentieth century (20C) and late twenty-first century (21C) using the same resolution of IFS that is used for operational medium-range weather forecasts (up to 10 days). This version of IFS has a horizontal spectral truncation of T1279, which translates to a gridbox size of approximately $16 \mathrm{~km}$ on a reduced Gaussian grid. There are 91 levels in the vertical. The model is integrated at a time step of $10 \mathrm{~min}$ and data are saved every $6 \mathrm{~h}$. 
For the Athena project, model version CY32r3 of the IFS was integrated at several horizontal resolutions (T159 or $125-\mathrm{km}$ grid, T511 or $39-\mathrm{km}$ grid, T1279 or 16-km grid, and T2047 or 10-km grid). Jung et al. (2012) found that while increasing resolution improved the extratropical cyclone and blocking event simulations, precipitation and tropospheric circulation were only improved in the tropics. Dirmeyer et al. (2012) found that the simulation of diurnal characteristics of the hydrologic cycle in the current climate by the low-resolution (T159) version of IFS were significantly poorer than for higher resolutions. The highest resolution (T2047) was not quite as good as T1279 in the net, but also has not been used operationally nor calibrated to the same degree as the other resolutions of the GCM. As a result, we show here only results for the T1279 simulations, although we have compared to results at T159 and find them to be qualitatively similar, except in regions of steep orography where T159 can produce spurious climatological features.

Both $20 \mathrm{C}$ and $21 \mathrm{C}$ simulations are performed here in "time-slice" mode with specified sea surface temperature (SST). The 20C simulation begins at 0000 UTC 1 January 1961 and continues for 47 years. Ocean boundary conditions for the 20C simulation are the same as used for the 40-yr European Centre for MediumRange Weather Forecasts (ECMWF) Re-Analysis (ERA40; Uppala et al. 2005). Here, $1.125^{\circ}$ monthly data are used before 1990, and weekly data beginning in 1990 have been interpolated linearly in time and to the higherresolution GCM grid in space. Daily SST from the ECMWF operational system are used starting in 2002. For the $21 \mathrm{C}$ simulation, the same time series of SST is used, but scaled using the difference of mean climatologies (2065-75 minus 1965-75) from the coupled Community Climate System Model version 3 simulation under the A1B climate scenario (Meehl et al. 2006).

Bechtold et al. (2008) describe the key updates to parameterizations in this version of IFS (ECMWF 2009). Of particular note for this study is the surface parameterization-the Hydrology Tiled ECMWF Scheme for Surface Exchanges over Land (HTESSEL). HTESSEL calculates a complete energy and water balance over land with subgrid representation of vegetation canopies and interception, open water, ice, and snow fractional coverage as a set of distinct tiles. Key to this study is the representation of soil moisture state and evapotranspiration. The soil column is discretized as four layers reaching a depth of $289 \mathrm{~cm}$, with the surface layer $7 \mathrm{~cm}$ thick. Roots are distributed among these layers depending on the vegetation type and provide a means to represent the extraction of moisture by plants, supplying transpiration to the total evapotranspiration. Direct evaporation from intercepted moisture, surface soil moisture, snow, and surface water bodies are also included.

\section{Water cycle in the GCM}

Figure 1 shows the 1961-2007 mean precipitation of the IFS simulation with observed SST (20C) in the left column for the annual mean (top), boreal winter [December-February (DJF); center], and boreal summer [July-August (JJA); bottom]. The right column shows the changes in the time-slice simulation (20712017) from the late twentieth-century simulation (21C minus 20C) in terms of percentage deviation.

IFS produces a good simulation of the patterns of the mean and annual cycle of precipitation for current climate, although precipitation is generally excessive over oceans and often slightly dry over land (Dirmeyer et al. 2012). The patterns of precipitation standard deviation closely resemble the mean fields (not shown).

The response of precipitation to a changing climate shows a number of important features. Most prominent are an increase in precipitation over polar and high-latitude regions, particularly during local winter, enhanced precipitation over the central Pacific (the socalled permanent El Niño signal), and decreased rainfall across most of the subtropics in both hemispheres, with strongly diminished rainfall in a band over the subtropical northern Atlantic, Caribbean, and Mexico. The large percentage changes evident over northern Africa and Arabia are on top of very small mean values and so are not remarkable. Other regional features worth noting are the broad areas of reduced warm season rainfall over many agricultural zones (North America, Europe, South Africa, as well as central Asia) and stronger seasonality over most monsoon areas (e.g., central South America, much of southern Asia, northern Australia, and southwestern Africa), except for the North American monsoon region, which suffers collapse. These patterns of precipitation changes are largely consistent with the results from the consensus of coupled model projections (Meehl et al. 2007).

Figure 2 shows more annual statistics of the $20 \mathrm{C}$ simulation (left column) and 21C - 20C (right column). The amplitude of the annual cycle is calculated as half the difference of the maximum and minimum from a time series of daily values representing the $47-y r$ mean annual cycle, which is then passed through two time filters-a centered 31-day average and then a centered 7-day average. The amplitude has a strong correspondence to the monsoon regions, obviously, although the convergence zones and storm tracks are still prominent. The change in amplitude has a great deal of structure, particularly over ocean, but is basically positive over land. 

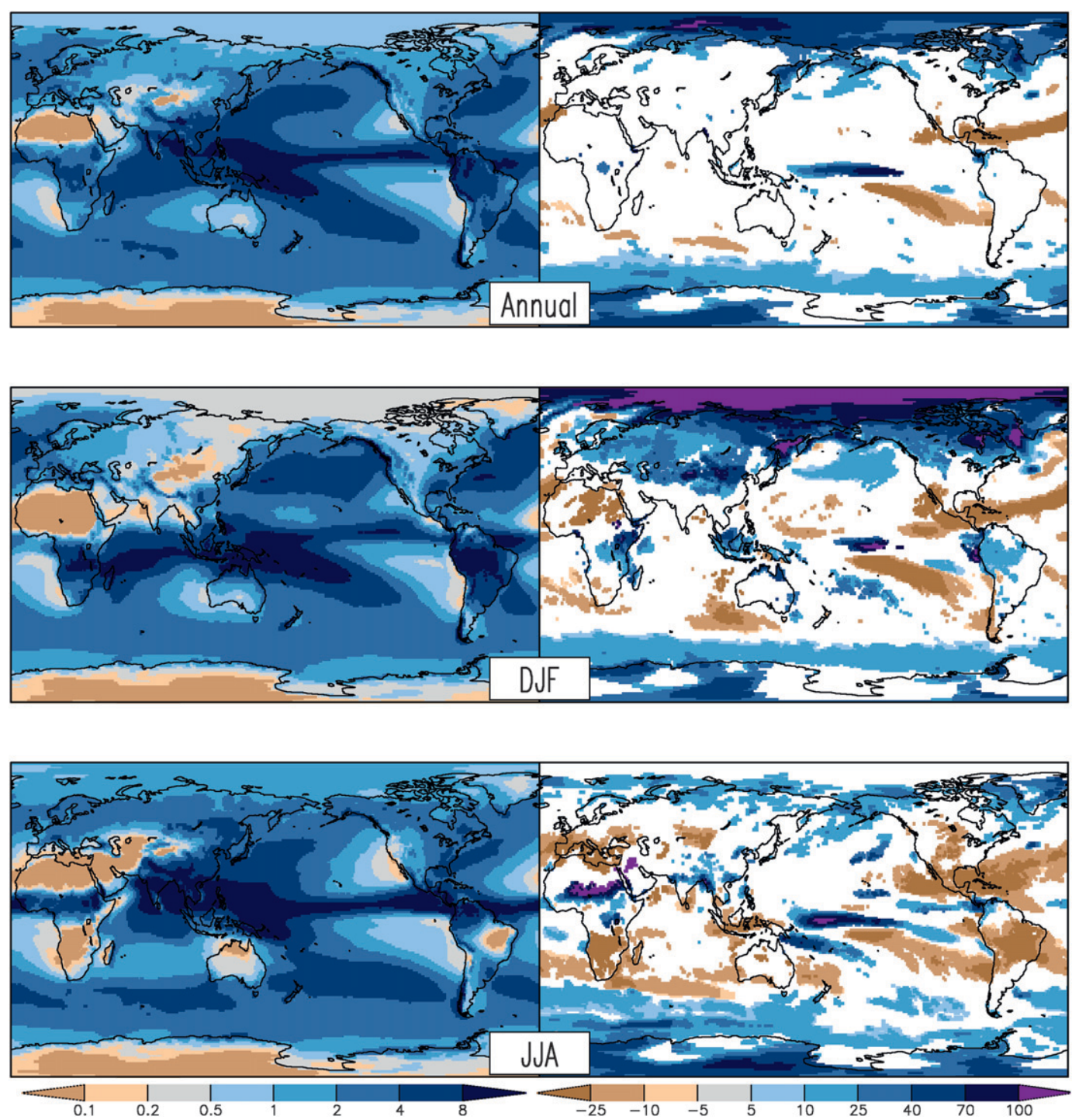

FIG. 1. (left) GCM precipitation for the $20 \mathrm{C}$ simulation $\left(\mathrm{mm} \mathrm{day}^{-1}\right.$ ) and (right) change from $20 \mathrm{C}$ to $21 \mathrm{C}$ (\%) for (top) the annual mean, (middle) DJF, and (bottom) JJA. Changes significant at the $95 \%$ confidence level are shaded.

Many of these regions of increased amplitude of the annual cycle correspond to regions of increased annual rainfall and are caused by a wetter wet season. However, for some regions, such as over the central United States, the increase of amplitude is caused by a drier dry season. We will investigate the changing drought signal later in this paper.

The phase of the annual cycle is defined as the Julian date of the maximum value in the smoothed time series of the mean annual cycle. Figure 2 groups these dates by month, but the changes are shown as the shift in days of the date of maximum value. Shades of blue predominate, suggesting that in many locations the peak rainfall occurs earlier in the year in the $21 \mathrm{C}$ case than in 20C. Based on a 100-member bootstrap estimate of uncertainty in the phase of the annual cycle, $14 \%$ of land points experience a significant shift $(p=0.05)$ to an earlier peak.

Changes in the magnitude of the mean diurnal cycle of precipitation are shown in Fig. 3 for boreal winter and summer seasons separately. The strongest diurnal cycles are associated with convective precipitation and are located in warm season rainy zones. Over land, changes are predominantly negative, reflecting well the changes in mean precipitation in Fig. 1. However, there are decreases in southern tropical Africa and South America in DJF where mean rainfall increases; likewise for parts of Southeast Asia during JJA. There are some continental 

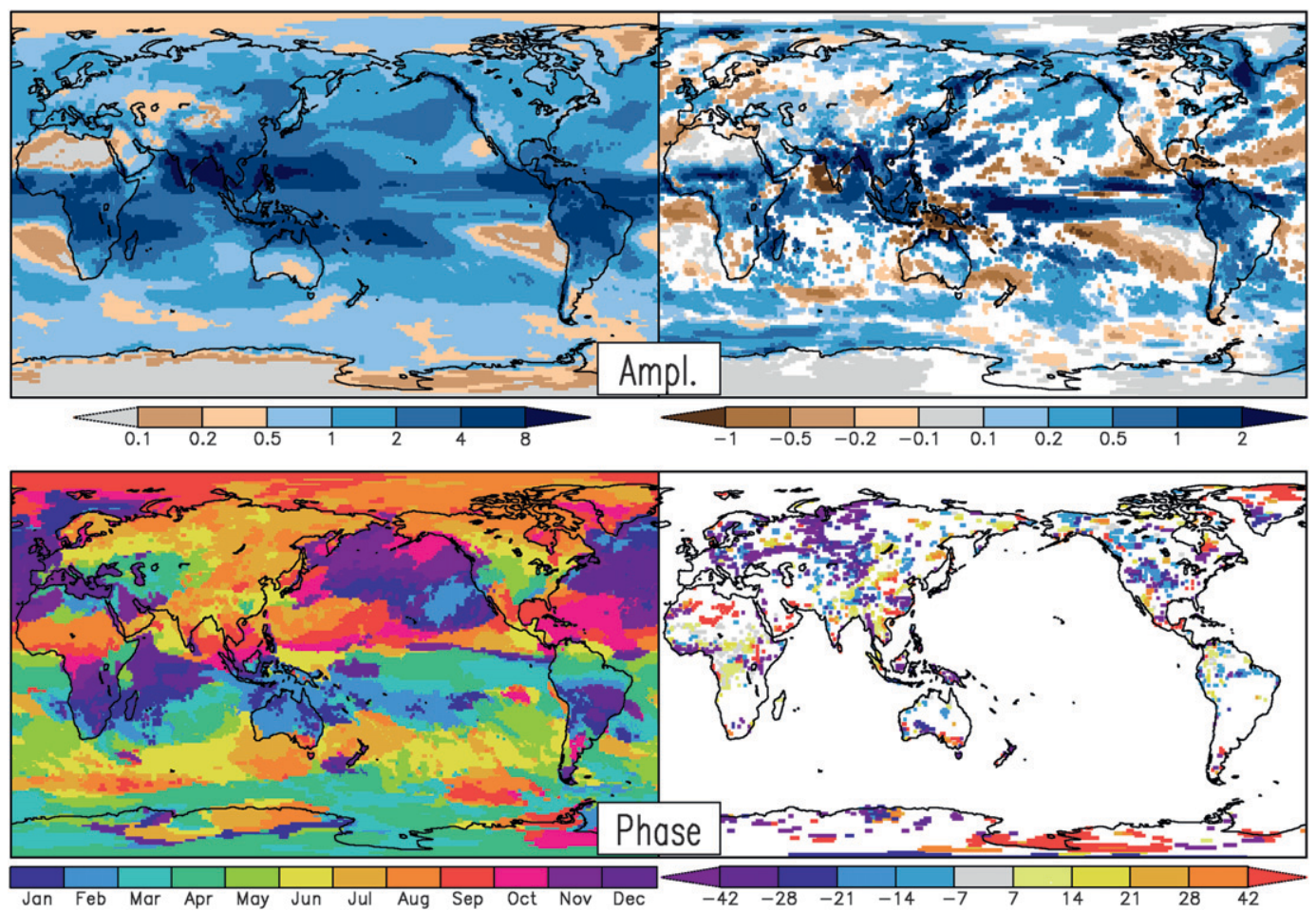

FIG. 2. (top) The amplitude of the annual cycle of precipitation $\left(\mathrm{mm} \mathrm{day}^{-1}\right)$ and (bottom) the phase of the annual cycle [showing (bottom left) time of peak rainfall and (bottom right) change in days] for (left) the 20C simulation and (right) change from $20 \mathrm{C}$ to $21 \mathrm{C}$. Changes significant at the $95 \%$ confidence level based on a 100-member bootstrap estimate of variance are shaded; only land points are shaded for the change of phase.

locations, such as sub-Saharan Africa and southern Tibet during JJA, where the model projects the diurnal cycle to intensify.

The left column of Fig. 4 shows the distribution of the probabilities of 6-hourly precipitation in the $20 \mathrm{C}$ simulation in five categories and the changes in these probabilities. The values tallied for all seasons are shown. The sum at any location across the five left-hand panels equals $100 \%$. Six-hourly precipitation in excess of $4 \mathrm{~mm}$ of liquid water is most prevalent in the convergence zones, storm tracks, rain forests, and the region of the Asian monsoon. Heavy precipitation is exceedingly rare over arid regions, including polar areas. In the IFS model, periods with no precipitation are largely a terrestrial phenomenon. The extensive areas of rare dry intervals over oceans are unrealistic, but typical of GCMs with parameterized clouds and convection. Most oceanic regions commonly have 6-hourly precipitation totals between 0.25 and $4 \mathrm{~mm}$, while the drier stratus deck regions tend to have precipitation totals between 0 and $0.25 \mathrm{~mm}$. Most land areas have a roughly uniform distribution of days among the classes, although areas of the Amazon basin and Indonesia behave like the oceanic tropical rain zones that rarely have dry days.
The changes in each category are shown in the right column of Fig. 4. In short, most land areas have an increase in probability of both extremes, 6-h intervals with no precipitation (particularly in the midlatitudes), and with heavy precipitation (prevalent in the tropics). Periods with light or moderate precipitation become less frequent in most locations. Polar areas show a marked shift toward heavier precipitation, which is consistent with many other climate change model results. Over ocean, there is a mixture of changes largely mirroring the shifts in mean precipitation, although there is a tendency toward reduced incidences of moderate rainfall (between 0.25 and $4 \mathrm{~mm}$ per $6 \mathrm{~h}$ ) in most locations.

Figure 5 shows the change in precipitation from what we might term "flash flooding" in the model from $20 \mathrm{C}$ to $21 \mathrm{C}$, quantified in this study as the mean precipitation during the five 6-h intervals with the highest rates during the 47-yr simulations. The globe is dominated by increases in this quantity, reflecting a widespread increase at the extreme wet tail of the precipitation distribution. The most intense increases are mainly over oceans and tropical land regions. The greatest increases of all, over $100 \mathrm{~mm}$ per $6 \mathrm{~h}$, are during JJA in the western Pacific and Bay of Bengal associated with the model's 

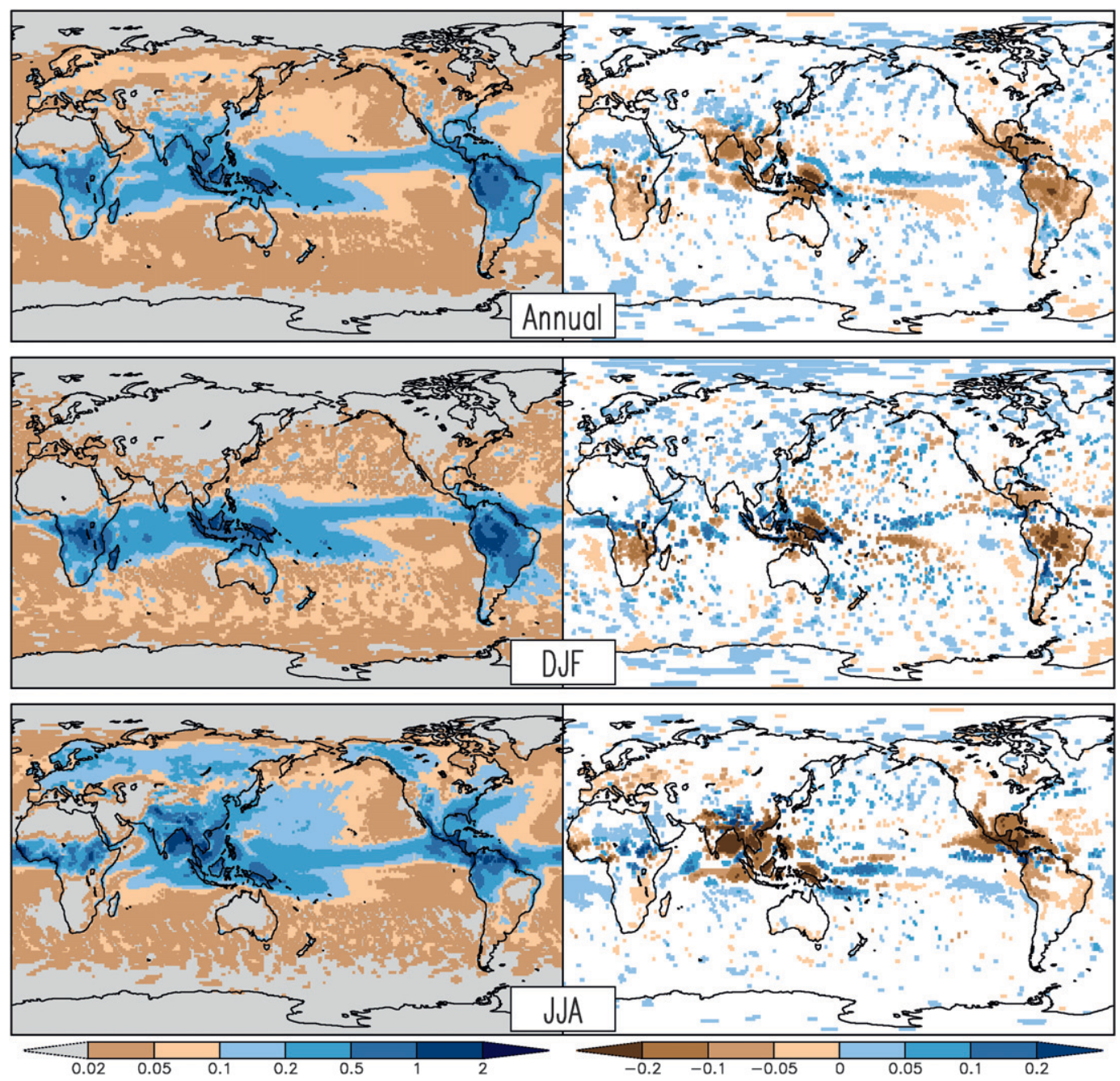

FIG. 3. (left) Selected statistics of the GCM precipitation for the $20 \mathrm{C}$ simulation and (right) change from $20 \mathrm{C}$ to $21 \mathrm{C}$ for the amplitude of the diurnal cycle during (middle) DJF and (bottom) JJA and (top) calculated for the entire year. Units are $\mathrm{mm}(6 \mathrm{~h})^{-1}$. Changes significant at the $95 \%$ confidence level are shaded.

manifestation of tropical cyclones. However, increases predominate over most continental areas as well, particularly during the warm/wet season. The only largescale areas showing a decrease in extreme precipitation events are over some deserts and some monsoon regions during the dry season. The standard deviation of 6-hourly precipitation (not shown) strongly resembles this figure, as that quantity is strongly influenced by the extremes.

To quantify changes in the incidence of drought in the model, we have looked at each monthly (not shown) and 3-month season around the year and have defined the threshold of drought for each as the precipitation in the fifth driest year of the 47-yr simulation for 20C, corresponding to approximately the $10 \%$ limit in the probability distribution of precipitation at each location and time (cf. Gibbs and Maher 1967). We then examine the $21 \mathrm{C}$ simulation for the same month or season and count the number of years for which the precipitation is less than or equal to this drought threshold value defined from the 20C run. An increase (more than 5 years out of 47) indicates a greater incidence of drought conditions, while a decrease suggests fewer. Figure 6 shows the results for JJA and DJF, which are largely representative of the evolution of the annual cycle in both monthly and seasonal data. Regions receiving less than $0.1 \mathrm{~mm}$ of precipitation during the $20 \mathrm{C}$ season are masked out.

During boreal summer, there are broad regions in both hemispheres where the incidence of drought has increased markedly (brown colors), including most of Europe, a broad swath of North America including most of the important agricultural regions, central Asia, most 

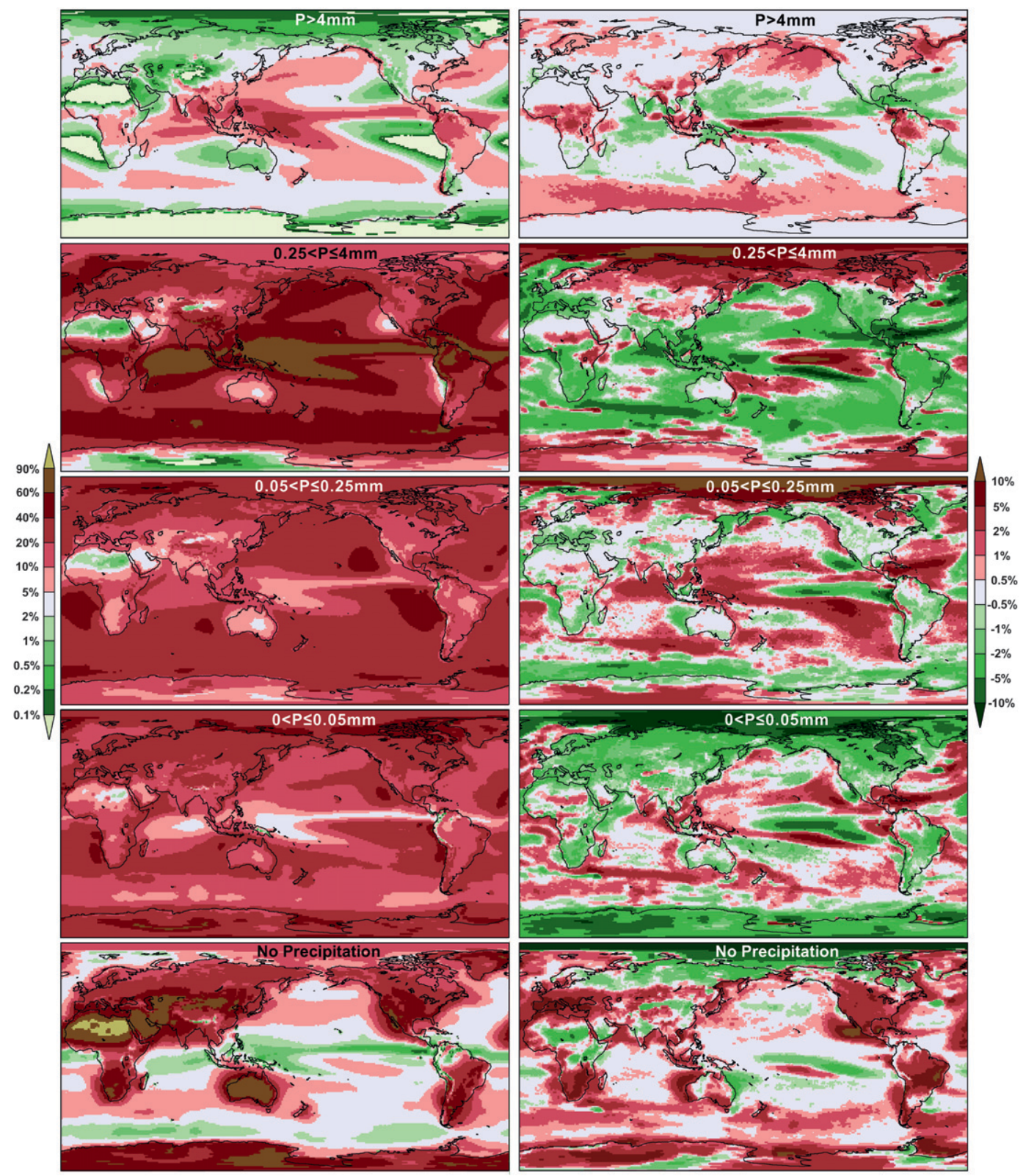

FIG. 4. Percentage of 6-h intervals with precipitation from the $20 \mathrm{C}$ simulation in each of five categories of intensity, (left) indicated at the top of each panel and (right) change in \% $(21 \mathrm{C}-20 \mathrm{C})$.

of South America, and southern Africa. Seasons of severe drought are less likely across the high latitudes and much of the Sahel.

During austral summer, regions of increased frequency of drought are limited to North and South Africa, Chile, the Brazilian Highlands, the Sonoran Desert, southeastern United States, Caribbean, and western and southern Mexico. In these months there is a greatly reduced area of the globe where drought incidence decreases. However, across much of the Northern Hemisphere this is the drier part of the year. The regions in both panels of
Fig. 6 compare consistently with precipitation changes in Fig. 1.

Looking beyond precipitation in the water cycle, Fig. 7 shows the $20 \mathrm{C}$ seasonal means and changes $(21 \mathrm{C}$ minus 20C) for terrestrial surface latent heat flux and surface layer volumetric soil wetness. An interesting contrast is seen in the climate change signal. Most locations show an increase in latent heat flux in both seasons ( $82 \%$ of land outside Antarctica during DJF and 75\% in JJA), yet soil wetness decreases predominate over most regions. The patterns are similar, with the largest increases 

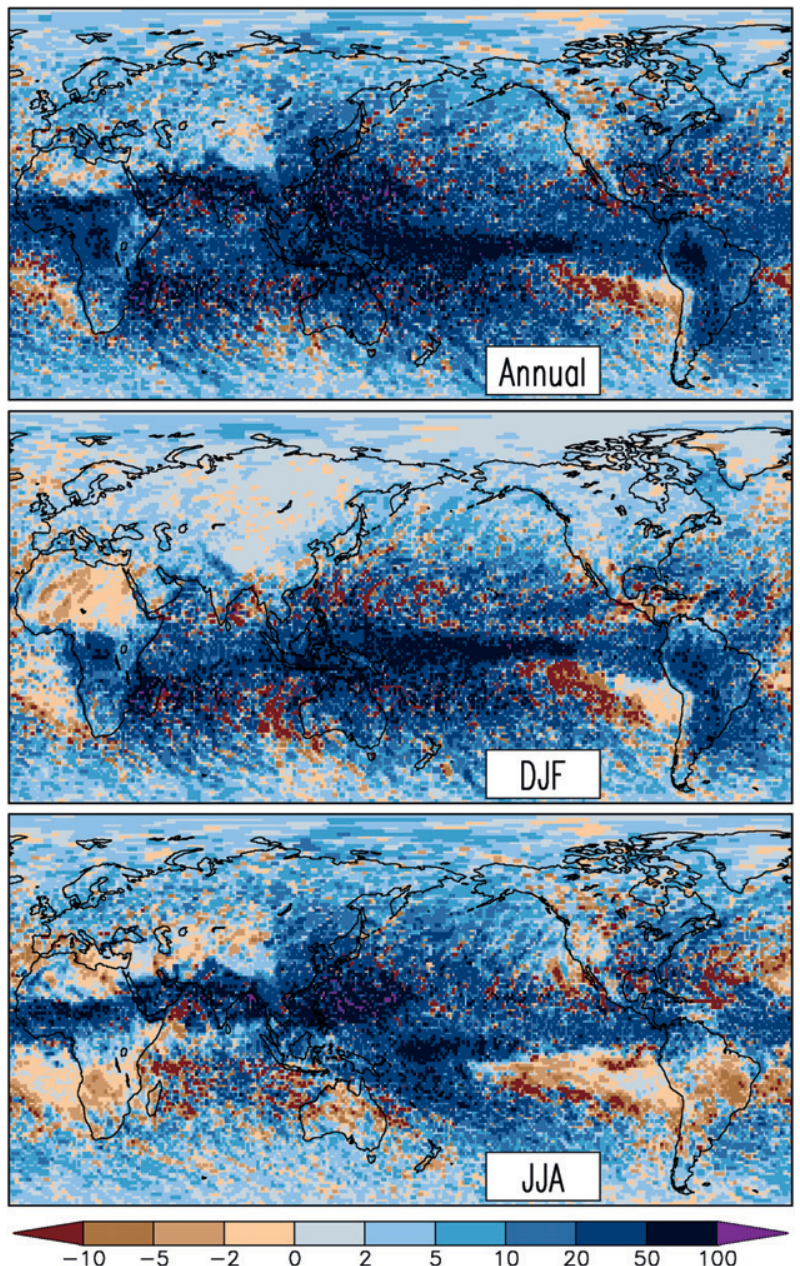

FIG. 5. Change $(21 \mathrm{C}-20 \mathrm{C})$ in the mean precipitation $(\mathrm{mm})$ during the five wettest 6-h intervals for (top) the entire year, (middle) DJF only, and (bottom) JJA only.

in both quantities collocated and reflecting the precipitation changes in Fig. 1, but the major decreases are not as well correlated. The main difference is in the position of the zero line-warmer conditions drive greater evapotranspiration from the land surface, yet also allow for greater depletion of soil moisture.

All of these statistics were also calculated for a lowresolution (T159; approximately $1.125^{\circ}$ ) pair of simulations and the same general results are found, although some features in the vicinity of steep or complex terrain (e.g., over the Ganges River basin) differ and are probably artifacts of the poorly resolved topography at T159.

The results shown here are consistent with those found in fully coupled integrations of climate change scenarios, although here we focus on subdiurnal instead of daily or monthly precipitation data and a GCM run at much higher spatial resolution than traditional climate change simulations. We find interesting changes
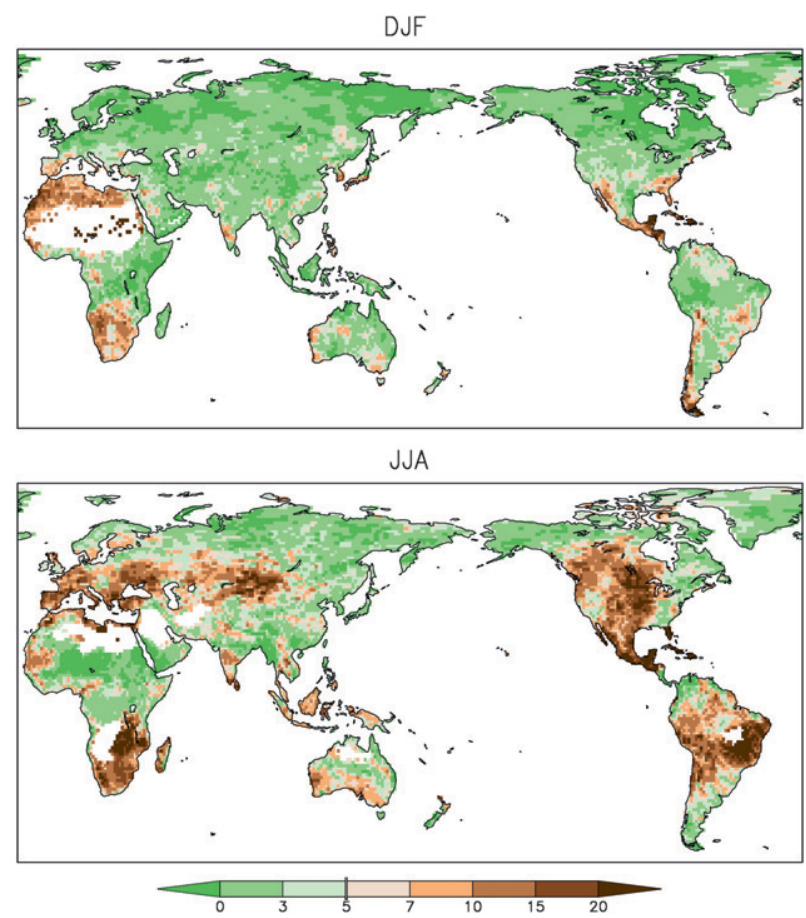

FIG. 6. The number of years, out of 47 , when the seasonal precipitation over land from the $21 \mathrm{C}$ simulation is less than the fifth lowest total from the 20C simulation. (top) DJF and (bottom) JJA. Locations with precipitation rates less than $0.1 \mathrm{~mm} \mathrm{day}^{-1}$ are masked out.

in statistics; particularly the tendencies over many land areas for increased incidence of drought, model analogs to flash flooding, an earlier peak to the rainy season, and increased variance of precipitation. These results hint at the possibility that enhanced feedbacks between land and atmosphere may be contributing to these changes, particularly since stronger positive (or weaker negative) feedbacks might be expected to result in a higher incidence of extremes. In the next section, we diagnose the changes in coupling between soil wetness, evaporation, and the atmosphere via the water cycle.

\section{Diagnosis of coupling}

\section{a. Land surface drivers}

Previous studies have identified key metrics for determining the potential strength of land-atmosphere coupling. Koster et al. (2002) introduced a metric based on the behavior of an ensemble of seasonal simulations that has been widely used (e.g., Koster et al. 2006; Guo et al. 2006; Seneviratne et al. 2006a), sometimes with variations (e.g., Wang et al. 2007). However, long climate change simulations are not conducive to this approach. For the land surface branch of the hydrologic 

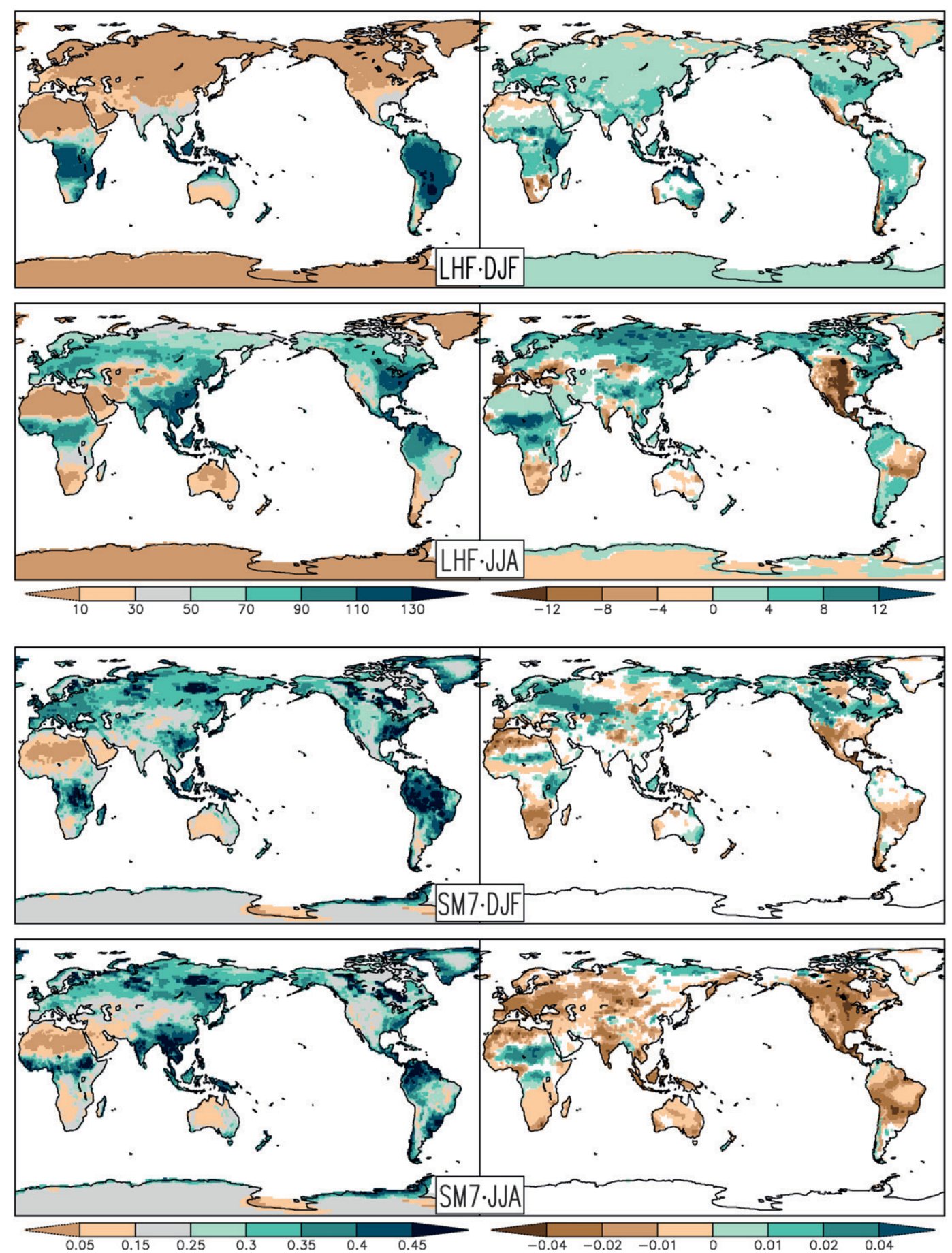

FIG. 7. (left) $20 \mathrm{C}$ simulation and (right) change from $20 \mathrm{C}$ to $21 \mathrm{C}$ for (top) the annual mean latent heat flux ( $\mathrm{W} \mathrm{m}^{-2}$ ) for DJF and JJA, and (bottom) volumetric soil wetness in the top 7-cm model layer for DJF and JJA. Changes significant at the $95 \%$ confidence level are shaded.

cycle, a positive local temporal correlation between soil moisture and evapotranspiration is necessary for the transmission of information about soil wetness anomalies to the atmosphere (Dirmeyer et al. 2009). Guo et al. (2006) made the point that a pathway for soil moisture anomalies to affect surface fluxes would have little impact on the atmosphere if there was not also substantial variability of surface fluxes in time. To capture 

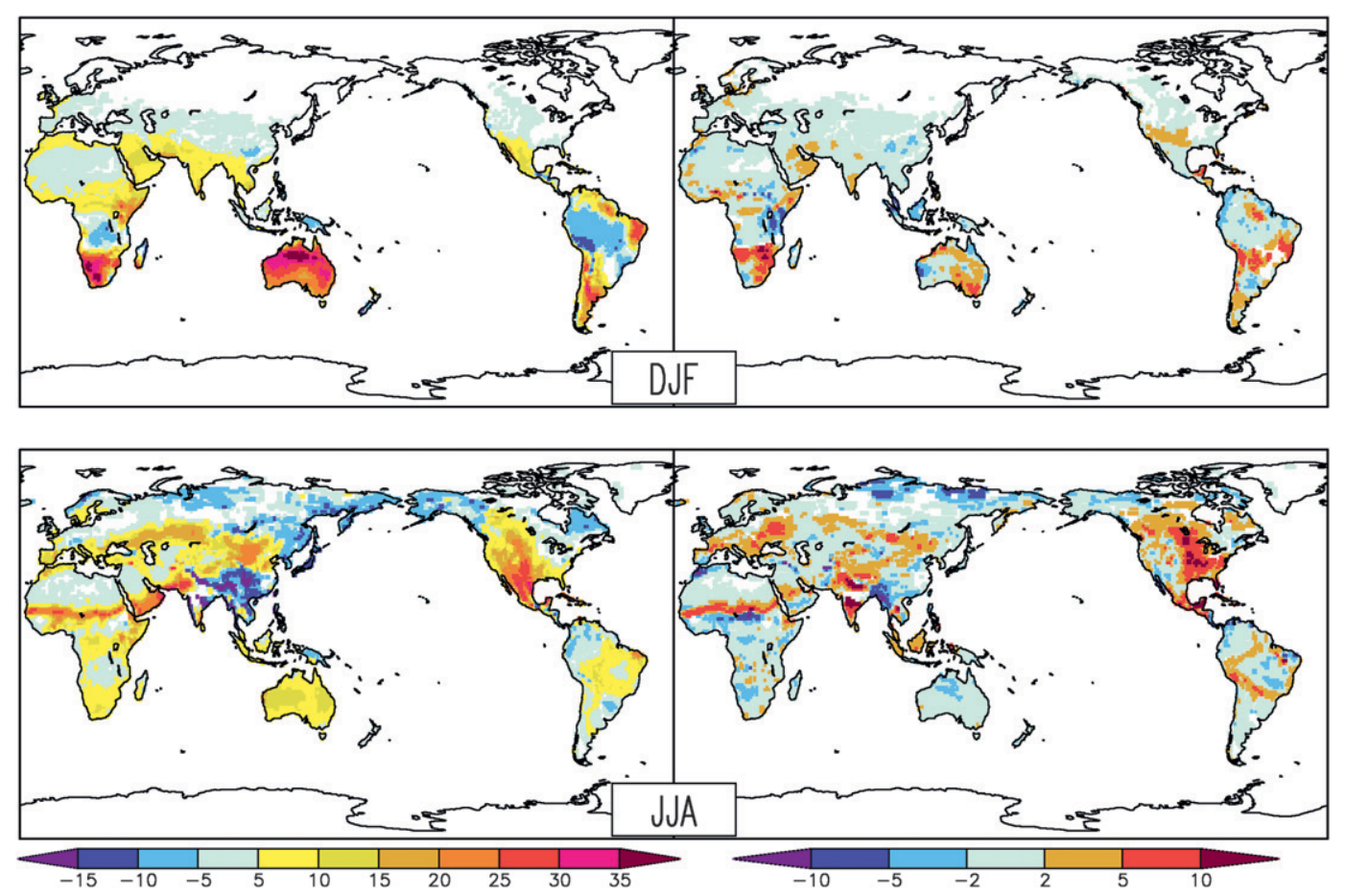

FIG. 8. (left) $20 \mathrm{C}$ simulation and (right) change from $20 \mathrm{C}$ to $21 \mathrm{C}$ for the LCI between daily surface soil moisture and latent heat flux $\left(\mathrm{W} \mathrm{m}^{-2}\right.$ ) for (top) DJF and (bottom) JJA.

this aspect, we use the land surface coupling index (LCI) of Dirmeyer (2011) calculated with daily data. The LCI is the product of the standard deviation of soil moisture (top 7-cm layer in IFS) and the slope of the linear regression of surface latent heat flux on soil moisture. An alternative but mathematically equivalent formulation is the product of the standard deviation of the latent heat flux and the correlation between latent heat flux and soil moisture. Values are only considered where the correlation between soil moisture and latent heat flux is significant at the $99 \%$ confidence level.

Figure 8 shows the global distribution of LCI for winter and summer in the $20 \mathrm{C}$ simulation and its change in $21 \mathrm{C}$. The JJA pattern is much like the distribution of "hot spots" of land-atmosphere coupling from Koster et al. $(2004,2006)$. The seasonal cycle shows that the greatest sensitivity of surface fluxes to soil moisture variation is in the areas between arid and humid climates and follows the pattern of the monsoons. These regions have the strongest control of soil moisture on fluxes (strong negative indices are found here when sensible heat flux is regressed on soil wetness; not shown). Negative values are found after snowmelt in high latitudes and in wet tropical regions. The region centered on southern China is a particularly strong area of negative LCI (also in the seasons not shown), suggesting land states are typically not a driver of the hydrologic cycle there. DJF shows large values over much of Australia and South Africa. This has also been seen in other global data (Dirmeyer 2011) and results from large interannual variability in precipitation causing large standard deviations of soil moisture. So in the Southern Hemisphere, the land-atmosphere coupling effect acts more strongly on interannual than intraseasonal to seasonal time scales.

For the changes (21C minus 20C) in LCI, masking is based on the significance of $21 \mathrm{C}$ correlations between soil moisture and latent heat flux. At first glance, there is a preponderance of positive changes in each season (62\% of shaded land areas outside Antarctica are positive in DJF and 55\% in JJA), suggesting an overall trend toward increased coupling between soil moisture and surface fluxes. Global average values of LCI increase $0.7 \mathrm{~W} \mathrm{~m}^{-2}$ in DJF and $0.6 \mathrm{~W} \mathrm{~m}^{-2}$ in JJA. We find that there is an increase in variance of soil moisture and evapotranspiration (ET) over most regions that have positive values of LCI in the 20C simulation (not shown). There is often an extension of existing hot spots into the humid regimes, although in the Sahel during JJA and over Australia the expansion seems to be toward arid zones. Intensification in the relationship between soil moisture and latent heat flux predominates around the margins of positive LCI (not shown), principally accounting for the expanded area of coupling. Areas of weakened coupling are limited and mostly found in low 

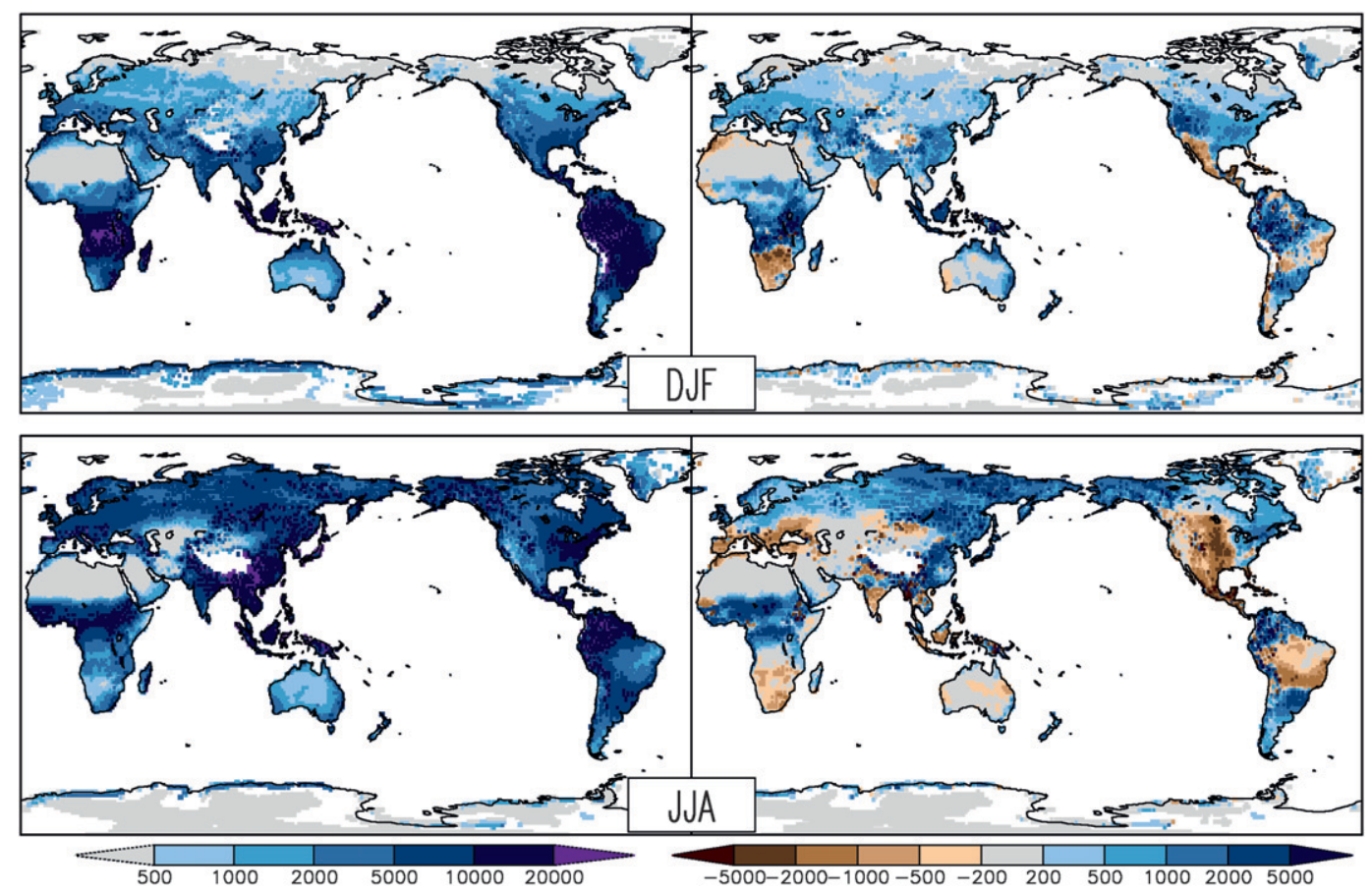

FIG. 9. As in Fig. 8 for the energy input to the PBL from surface evapotranspiration (latent heat fluxes) per unit mass of $\operatorname{air}\left(\mathrm{J} \mathrm{kg}^{-2}\right)$.

latitudes or core monsoon regions. Exceptions include the Arctic coast of Asia in summer, where snowmelt comes earlier.

LCI is analogous to the land surface contribution to land-atmosphere coupling strength (Guo et al. 2006, their Fig. 5). This result suggests the net effect of climate change on the terrestrial leg of the hydrologic cycle is toward an enhanced potential of land surface anomalies to feedback on climate. This finding is consistent with the study of Seneviratne et al. (2006b) that was limited to Europe. However, this trend delineates a necessary but not sufficient condition for increased land surface controls on climate. Can changes in surface fluxes communicate to atmospheric phenomena such as precipitation?

\section{b. Atmospheric response}

To assess the changes in the atmospheric branch of the feedback loop, we apply the local coupling metrics for the PBL of Santanello et al. $(2009,2011)$ to every land grid point in both $20 \mathrm{C}$ and $21 \mathrm{C}$ simulations. Specifically, the contribution of surface heat fluxes to the heat content of the PBL is quantified over the daytime portion of the diurnal cycle, approximated as the period between 0700 and 1900 LST. At each land grid point, we fit the diurnal harmonic to the four-times-daily near-surface temperature and humidity using the method described in the appendix of Dirmeyer et al. (2012) and then choose the values from the harmonic that correspond to 0700 and 1900 LST. For the daytime mean values of PBL depth and surface heat fluxes required by the method of Santanello et al. (2009), linear interpolation from four-times-daily output is used. We found errors from these approaches to be less than $10 \%$ in a substantial majority of cases when compared to estimates using hourly data. The mean surface heat fluxes over that period are divided by the mean depth of the PBL and scaled to render units of energy $\left(\mathrm{J} \mathrm{kg}^{-1}\right.$ or $\left.\mathrm{m}^{2} \mathrm{~s}^{-2}\right)$. For surface evapotranspiration, this is equivalent to the change in specific humidity in the PBL times the latent heat of vaporization. This change in PBL energy affects convective triggering (Findell and Eltahir 2003; Ferguson and Wood 2011) but may be counterbalanced by advection or entrainment at the top of the PBL (Santanello et al. 2009).

Figure 9 shows the seasonal energy input to the PBL per unit mass of air from surface evapotranspiration and the change from the $20 \mathrm{C}$ simulation to $21 \mathrm{C}$. The $20 \mathrm{C}$ distributions of this moist energy naturally resemble maps of surface latent heat flux, except that the energy input is intensified where boundary layer depths are shallow, and diffused where the PBL is deep. The change in this term from $20 \mathrm{C}$ to $21 \mathrm{C}$ is predominantly positive, as were latent heat fluxes in Fig. 7, but there are key regions where the moist energy declines. During DJF, Mexico, Morocco, South Africa, and several areas in 

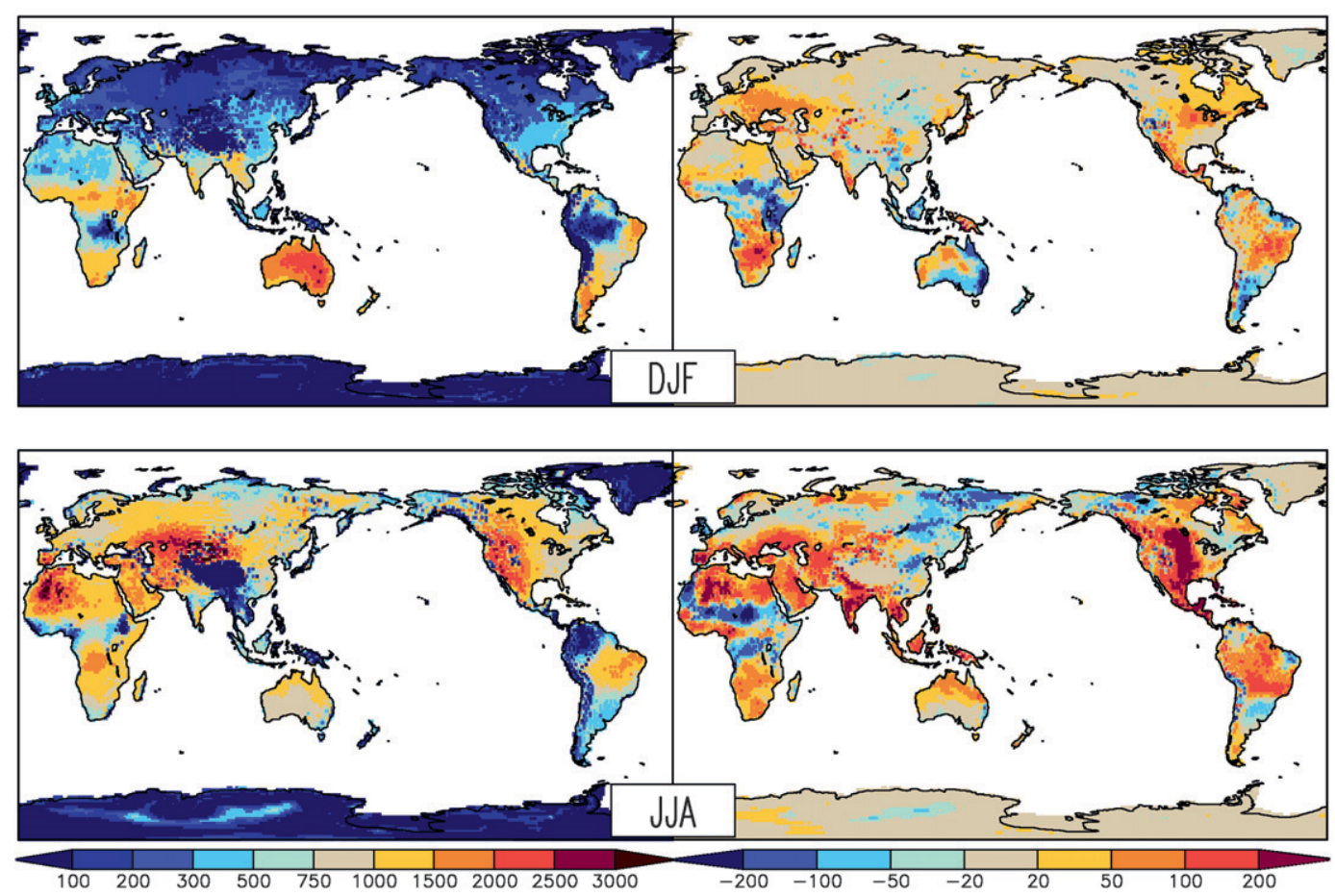

FIG. 10. As in Fig. 8 for mean depth (m) of the PBL during dry days (precipitation $<0.1 \mathrm{~mm} \mathrm{day}^{-1}$ ).

South America see marked declines. There are large increases over much of the western United States, Amazon basin, Pampas, central and eastern Africa, and Indonesia. During boreal summer, there are broad declines over central North America from Mexico to central Canada, the Mediterranean region, India, Indonesia, South Africa, and the dry-season area of South America. Increases are seen in the monsoon regions of Africa, East Asia, northern South America, as well as the eastern United States and Canada, the Pampas, and across nearly all of the Northern Hemisphere high latitudes. It should be noted that the moist energy from the surface shown here includes only days with precipitation less than $1 \mathrm{~mm} \mathrm{day}^{-1}$, just as Santanello et al. $(2009,2011)$ restrict calculations to only dry days.

These differences must be driven by changes in the surface latent heat flux or the PBL depth. Figure 10 shows the global distribution of the mean PBL depth (days of precipitation under $1 \mathrm{~mm} \mathrm{day}^{-1}$ only) for these seasons in the $20 \mathrm{C}$ simulation and its change in the $21 \mathrm{C}$ simulation. PBL depths are low where the climate is cold or wet and high in warm and dry locations. Most of the changes from $20 \mathrm{C}$ to $21 \mathrm{C}$ are increases-more than $200 \mathrm{~m}$ in some areas. Excluding Antarctica, 30\% of the land area in DJF and $42 \%$ in JJA have increasing PBL depths of at least $20 \mathrm{~m}$. Decreases in PBL depth are confined to subtropical Africa and summer seasons on the eastern and southern coasts of Australia, Patagonia, northeastern China, and far eastern Russia. Approximately $63 \%$ of the globe has a deepening of the PBL in each season.

Increasing PBL depths will tend to weaken the surface energy contribution to the PBL by distributing it over a greater mass of air. Comparing Figs. 9 and 10, we see the areas of decreasing moist energy correspond to the areas where PBL depth has grown the most. In desert regions, surface evapotranspiration is negligible and so are changes in moist energy. The predominance of positive changes in moist energy corresponds to areas of increased evapotranspiration.

These maps do not indicate, however, whether there is increased sensitivity of the atmosphere to changes in surface fluxes, particularly as they relate to soil moisture. The formulation of the moist energy quantity shown in Fig. 9 lends itself to application of the LCI in place of the surface latent heat flux, since each has the same units of $\mathrm{W} \mathrm{m}^{-2}$. The resulting estimate synthesizes both land surface and PBL branches of the coupling pathway of the water cycle into a single variable, shown in Fig. 11. The left panels describe the impact of the LCI on the PBL-large positive values suggest areas where an amply strong control of surface fluxes by soil moisture variance feed into a sufficiently shallow PBL to create a strong coupling of soil moisture to PBL properties. There is strong resemblance with Fig. 8, but the highest values of LCI are moderated as they almost always 

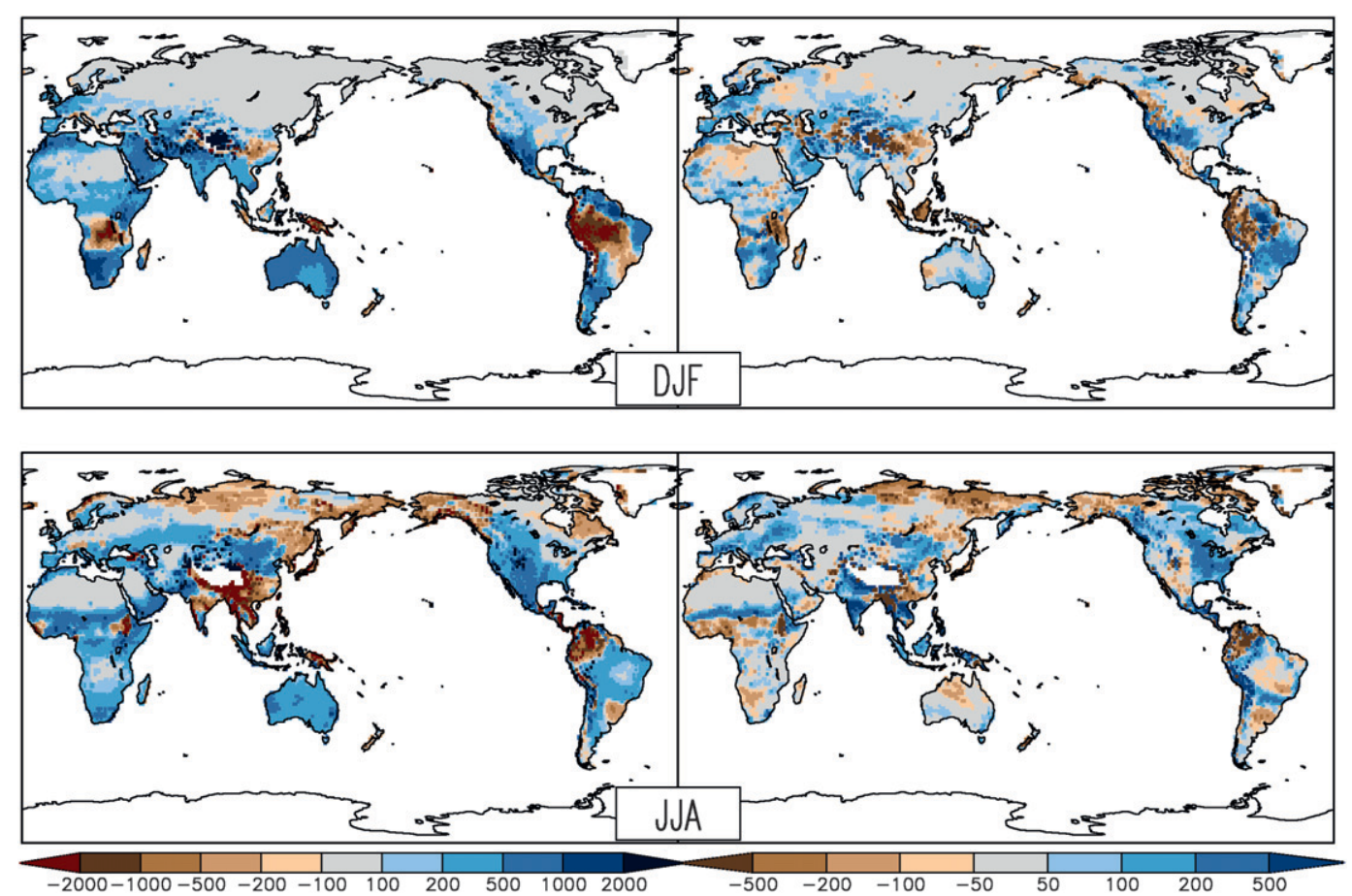

FIG. 11. As in Fig. 9, except the LCI is used instead of the surface latent heat flux for the calculation of energy input (see text for full explanation).

occur in areas with relatively deep PBLs (Fig. 10). On the other hand, areas where the LCI is not particularly large may still have important land-atmosphere coupling because the top of the PBL (and cloud base) is relatively close to the earth's surface. Negative values correspond directly to negative LCI, and thus denote regions where, in the mean, soil moisture is not a determinant of atmospheric conditions.

The right panels of Fig. 11 show the change in this synthesized coupling index in a changing climate. Despite the tendency toward deeper PBLs over most of the globe, there is a net increase in the control of soil moisture on PBL properties. Deepening PBLs only temper the increases in LCI, but do not appear to reverse their effects. Sixty-one percent of the land area has an increase in LCI during DJF and $58 \%$ has an increase in JJA. The strongest increases in soil-moisture-to-PBL coupling occur in the regions of gradients in the $20 \mathrm{C}$ fields, expanding into areas that have weak or no coupling. However, there are significant areas that show a negative trend, largely located in regions where soil moisture is already not a driver of the atmosphere. The net effect is an expansion of the area of the globe where soil moisture variations are likely to lead to changes in the properties of the lower troposphere, but a reinforcement of the lack of land-atmosphere coupling in the core areas where it is already minimal.

\section{Discussion and conclusions}

We have examined multidecadal simulations of late twentieth- and late twenty-first-century climate in high-resolution climate simulations of the IFS global atmospheric model coupled to the HTESSEL land surface model. Although these are not coupled oceanatmosphere simulations, these runs are unique because of their high spatial resolution $(16 \mathrm{~km})$ and temporal output frequency (6 hourly). We have focused on the climate change signal in the water cycle.

First, we examined changes in precipitationspecifically, changes in extremes and variance. Changes in seasonal and annual mean rainfall reflect the consensus findings of other climate change simulations. There is broad drying in much of the subtropics, increased precipitation at high latitudes, and some notable shifts in the vicinity of monsoons, particularly over North America. Many locations see the peak of their rainy seasons shifted days to weeks earlier in the $21 \mathrm{C}$ simulation. There is an amplification of the annual cycle of precipitation over most land areas but often a decrease in the magnitude of the diurnal cycle. The frequency distribution of precipitation shifts, with most land locations seeing greater likelihood of both rain-free and heavy rain intervals. Flash floods, defined here as the precipitation that comes in the wettest of 6-h intervals, 
become more severe in most locations around the globe. Meanwhile, the incidence of $10-\mathrm{yr}$ return period seasonal droughts, based on the $20 \mathrm{C}$ simulation, increases in many areas during boreal summer in the $21 \mathrm{C}$ run, although during boreal winter almost all locations see a reduction in drought frequency.

We then looked beyond precipitation to the land surface component of the water cycle and examined metrics of land-atmosphere coupling. A land coupling index (LCI) based on the sensitivity of surface latent heat fluxes to typical local soil moisture variations well reflects the pattern of "hot spots" between humid and arid climates deduced from ensembles of seasonal climate simulations in the Global Land-Atmosphere Coupling Experiment (GLACE) modeling project. Changes in LCI into the late twenty-first century suggest that the sensitivity of surface fluxes to soil moisture will expand into many regions that today have marginal sensitivity. Most of these areas are in the more humid locations, although over Africa the hot spots expand toward the deserts. We then look at the effects of surface fluxes on the PBL and find that although the boundary layer deepens over many land areas in the $21 \mathrm{C}$ case compared to 20C, the amount of latent heat flux per unit mass into the PBL usually increases. We combine the LCI with this estimate of moist energy in the PBL to deduce that, over many locations, the growing hot spots of soil moisture-surface flux coupling are not negated by the deepening PBL. Furthermore, the sensitivity to soil moisture variations of PBL energy content from surface fluxes does increase over a much larger area than it decreases.

Are the changes in land-atmosphere coupling-and thus changes in feedbacks between soil moisture, surface fluxes, and the PBL-responsible for any of the changes in precipitation? This can only be answered definitively in a climate model framework via sensitivity studies. However, given that the identified feedbacks are mostly positive, they may be contributing to the broadening of the probability distribution of precipitation, with increased likelihood of both very wet and dry intervals.

It should be noted that while surface latent heat flux moistens the PBL, it is the sensible heat flux that contributes to its growth, and only after its top has penetrated the lifting condensation level can convective clouds and precipitation form. Santanello et al. (2009, 2011) examine the combined effects of heat and moisture fluxes, including lateral advection and entrainment at the top of the PBL, in determining the importance of the land surface state for determining PBL characteristics. Findell and Eltahir (2003) demonstrate that there are also negative humidity feedback regions where dry soils and high Bowen ratios are preferential for triggering convection. A thorough examination of the role of land-atmosphere coupling in a changing climate should consider the full range of interactions and not the water cycle in isolation.

Here, the basis of an analysis of the shifting interaction between land and atmosphere in a changing climate has been presented. We have tried to point out that the results of these simulations are as consistent to consensus climate change projections as any individual coupled climate model simulations, and thus we speculate that our findings at finer temporal scales in terms of land-atmosphere coupling though the water cycle are valid. However, this is nevertheless the result of a single model whose parameterizations may contribute to eccentric behaviors, and the feedbacks with the ocean are missing. Ideally, this type of analysis can be repeated with a large selection of coupled models run under the latest climate change scenarios.

Acknowledgments. The results described herein were obtained in the 2009/10 Athena Project-a computationally intensive project that was carried out using the Athena supercomputer at the National Institute for Computational Sciences (NICS), under the auspices of the National Science Foundation (NSF). Support provided by NICS and the NSF (Grants 0830068 and 0957884) is gratefully acknowledged. We also acknowledge the support of the ECMWF, which authorized provision of the IFS code, boundary, and initial conditions datasets and run scripts.

\section{REFERENCES}

Bechtold, P., M. Koehler, T. Jung, F. Doblas-Reyes, M. Leutbecher, M. J. Rodwell, F. Vitart, and G. Balsamo, 2008: Advances in simulating atmospheric variability with the ECMWF model: From synoptic to decadal time-scales. Quart. J. Roy. Meteor. Soc., 134, 1337-1351.

Betts, A. K., 2004: Understanding hydrometeorology using global models. Bull. Amer. Meteor. Soc., 85, 1673-1688.

Dirmeyer, P. A., 1999: Assessing GCM sensitivity to soil wetness using GSWP data. J. Meteor. Soc. Japan, 77, 367-385.

_ 2000: Using a global soil wetness data set to improve seasonal climate simulation. J. Climate, 13, 2900-2922.

- 2001: An evaluation of the strength of land-atmosphere coupling. J. Hydrometeor., 2, 329-344.

_ 2005: The land surface contribution to boreal summer season predictability. J. Hydrometeor., 6, 618-632.

_ 2006: The hydrologic feedback pathway for land-climate coupling. J. Hydrometeor., 7, 857-867.

_ 2011: The terrestrial segment of soil moisture-climate coupling. Geophys. Res. Lett., 38, L16702, doi:10.1029/2011GL048268.

— C. A. Schlosser, and K. L. Brubaker, 2009: Precipitation, recycling, and land memory: An integrated analysis. J. Hydrometeor., 10, 278-288.

— , and Coauthors, 2012: Simulating the hydrologic diurnal cycle in global climate models: Resolution versus parameterization. Climate Dyn., doi:10.1007/s00382-011-1127-9, in press. 
Douville, H., 2002: Influence of soil moisture on the Asian and African monsoons. Part II: Interannual variability. J. Climate, 15, 701-720.

- 2003: Assessing the influence of soil moisture on seasonal climate variability with AGCMs. J. Hydrometeor., 4, 10441066.

ECMWF, cited 2009: IFS documentation CY33r1. [Available online at http://www.ecmwf.int/research/ifsdocs/CY33r1/index.html.]

Ferguson, C. R., and E. F. Wood, 2011: Observed land-atmosphere coupling from satellite remote sensing and reanalysis. J. Hydrometeor., 12, 1221-1254.

Findell, K. L., and E. A. B. Eltahir, 2003: Atmospheric controls on soil moisture-boundary layer interactions. Part I: Framework development. J. Hydrometeor., 4, 552-569.

— - P. Gentine, B. R. Lintner, and C. Kerr, 2011: Probability of afternoon precipitation in eastern United States and Mexico enhanced by high evaporation. Nat. Geosci., 4, 434-439.

Gibbs, W. J., and J. V. Maher, 1967: Rainfall deciles as drought indicators. Bureau of Meteorology Bulletin, No. 48, Commonwealth Bureau of Meteorology, Melbourne, Australia, 84 pp.

Guo, Z., and Coauthors, 2006: GLACE: The Global LandAtmosphere Coupling Experiment. Part II: Analysis. J. Hydrometeor., 7, 611-625.

Jung, T., and Coauthors, 2012: High-resolution global climate simulations with the ECMWF model in Project Athena: Experimental design, model climate, and seasonal forecast skill. J. Climate, 25, 3155-3172.

Koster, R. D., and M. J. Suarez, 2001: Soil moisture memory in climate models. J. Hydrometeor., 2, 558-570.

- , and _ 2003: Impact of land surface initialization on seasonal precipitation and temperature prediction. J. Hydrometeor., 4, 408-423.

— , and - 2004: Suggestions in the observational record of land-atmosphere feedback operating at seasonal timescales. J. Hydrometeor., 5, 567-572.

_ , P. A. Dirmeyer, A. N. Hahmann, R. Ijpelaar, L. Tyahla, P. Cox, and M. J. Suarez, 2002: Comparing the degree of land-atmosphere interaction in four atmospheric general circulation models. J. Hydrometeor., 3, 363-375.

__ and Coauthors, 2004: Regions of strong coupling between soil moisture and precipitation. Science, 305, 1138-1140.

— , and Coauthors, 2006: GLACE: The Global Land-Atmosphere Coupling Experiment. Part I: Overview and results. J. Hydrometeor., 7, 590-610.

— , and Coauthors, 2010: The contribution of land surface initialization to subseasonal forecast skill: First results from a multi-model experiment. Geophys. Res. Lett., 37, L02402, doi:10.1029/2009GL041677.

— , and Coauthors, 2011: The second phase of the Global LandAtmosphere Coupling Experiment: Soil moisture contributions to subseasonal forecast skill. J. Hydrometeor., 12, $805-822$

Meehl, G. A., and Coauthors, 2006: Climate change projections for the twenty-first century and climate change commitment in the CCSM3. J. Climate, 19, 2597-2616.

—_, and Coauthors, 2007: Global climate projections. Climate Change 2007: The Physical Science Basis, S. Solomon et al., Eds., Cambridge University Press, 747-845.

Molteni, F., R. Buizza, T. N. Palmer, and T. Petroliagis, 1996: The ECMWF ensemble prediction system: Methodology and validation. Quart. J. Roy. Meteor. Soc., 122, 73-119.

Randall, D. A., and Coauthors, 2007: Climate models and their evaluation. Climate Change 2007: The Physical Science Basis, S. Solomon et al., Eds., Cambridge University Press, 589-662.

Santanello, J. A., C. D. Peters-Lidard, S. V. Kumar, C. Alonge, and W.-K. Tao, 2009: A modeling and observational framework for diagnosing local land-atmosphere coupling on diurnal time scales. J. Hydrometeor., 10, 577-599.

,-- , and —_ 2011: Diagnosing the sensitivity of local landatmosphere coupling via the soil moisture-boundary layer interaction. J. Hydrometeor., 12, 766-786.

Schär, C., D. Lüthi, U. Beyerle, and E. Heise, 1999: The soilprecipitation feedback: A process study with a regional climate model. J. Climate, 12, 722-741.

Schlosser, C. A., and P. C. D. Milly, 2002: A model-based investigation of soil moisture predictability and associated climate predictability. J. Hydrometeor., 3, 483-501.

Seneviratne, S. I., and Coauthors, 2006a: Soil moisture memory in AGCM simulations: Analysis of Global Land-Atmosphere Coupling Experiment (GLACE) data. J. Hydrometeor., 7, 1090-1112.

— D. Lüthi, M. Litschi, and C. Schär, 2006b: Land-atmosphere coupling and climate change in Europe. Nature, 443, 205-209.

— - T. Corti, E. L. Davin, M. Hirschi, E. B. Jaeger, I. Lehner, B. Orlowsky, and A. J. Teuling, 2010: Investigating soil moistureclimate interactions in a changing climate: A review. Earth Sci. Rev., 99, 125-161.

Uppala, S. M., and Coauthors, 2005: The ERA-40 Re-Analysis. Quart. J. Roy. Meteor. Soc., 131, 2961-3012.

Wang, G., Y. Kim, and D. Wang, 2007: Quantifying the strength of soil moisture-precipitation coupling and its sensitivity to changes in surface water budget. J. Hydrometeor., 8, 551-570. 